\title{
Clinical symptoms, hormone profiles, treatment, and prognosis in patients with gastric carcinoids
}

\author{
D Granberg, E Wilander, M Stridsberg, G Granerus, B Skogseid, K Öberg
}

\begin{abstract}
Background-Type 1 gastric carcinoids are associated with hypergastrinaemia and chronic atrophic gastritis, type 2 occur in patients with multiple endocrine neoplasia type 1 combined with ZollingerEllison syndrome, and type 3 lack any relation to hypergastrinaemia. Type 1 tumours are usually benign whereas type 3 are highly malignant.
\end{abstract}

Aims-To identify possible tumour markers in patients with gastric carcinoids.

Patients/method-Nine patients with type 1 , one with type 2 , and five with type 3 were evaluated with regard to symptoms, hormone profile, and prognosis.

Results-Plasma chromogranin A was increased in all patients but was higher $(p<0.01)$ in those with type 3 than those with type 1 carcinoids. All patients with type 3 carcinoids died from metastatic disease, but none of the type 1 patients died as a result of their tumours. One type 1 patient with a solitary liver metastasis received interferon $\alpha$ and octreotide treatment. Nine months later, the metastasis was no longer detectable. She is still alive eight years after diagnosis, without recurrent disease. This represents the only reported case of foregut carcinoid with an unresectable liver metastasis that seems to be have been cured by biotherapy.

Conclusions-Plasma chromogranin A appears to be a valuable tumour marker for all types of gastric carcinoid. Combination therapy with interferon $\alpha$ and octreotide may be beneficial in patients with metastasising type 1 gastric carcinoids.

Keywords: gastric carcinoids; chromogranin; histamine; interferon; octreotide

B Skogseid

K Öberg

Department of

Pathology

E Wilander

Department of Clinical

Chemistry

M Stridsberg

Department of Clinical Physiology, University

Hospital, Linköping,

Sweden

G Granerus

Correspondence to:

Professor Öberg.

Accepted for publication 4 February 1998 compassing bronchial, gastric, and duodenal carcinoids, may instead cause an atypical carcinoid syndrome with severe generalised flush, diarrhoea, cutaneous oedema, lacrimation, and bronchoconstriction. This is in part due to secretion of histamine. Histamine is metabolised and excreted in the urine mainly as tele-methylimidazoleacetic acid (MeImAA). ${ }^{2}$
(Gut 1998;43:223-228)

Human gastric carcinoid tumours have been identified as three main variants: types 1,2 , and 3. . $^{3-9}$

Type 1 (ECLoma) originate from the mucosal enterochromaffin-like (ECL) cells, which can synthesise and store histamine. These tumours, which are localised to the fundus or body and are mainly multiple, are associated with type A chronic atrophic gastritis, achlorhydria, and often pernicious anaemia. They are accompanied by antral G cell hyperplasia, intestinal metaplasia, and concomitant foci of endocrine cell hyperplasia and dysplasia in the surrounding extratumoral mucosa. ${ }^{36-12}$ Histologically, they stain positive with Grimelius' and Sevier-Munger's silver stains as well as for chromogranin A. ${ }^{3811} 13$ Around $2-9 \%$ of patients with pernicious anaemia develop gastric carcinoids. ${ }^{12}$ The pathogenesis of these tumours is claimed to be the trophic effect of the hypergastrinaemia on the ECL cells in the fundus/corpus, ${ }^{8} 101415$ but the chronic inflammation per se may also contribute to the hyperplasia of endocrine cells and the development of carcinoid tumours. ${ }^{8}$ Type 1 gastric carcinoids are considered to be the most benign of the three different types and have low malignant potential. ${ }^{7114}$ Metastases may, however, occur, most often to lymph nodes but also to the liver. Overall frequency of metastases has been reported to be $9-23 \%$ and liver metastases to be 3-5\%. ${ }^{816} 17$ Deaths from metastatic disease have also been described. ${ }^{17}$

Type 2 carcinoids occur in patients with hypergastrinaemia due to the Zollinger-Ellison syndrome in combination with multiple endocrine neoplasia type 1 (MEN 1). They are usually multiple and sometimes metastatic at diagnosis. $^{5718}$

Type 3 (mixed cellular composition) carcinoids are not associated with hypergastrinaemia. They usually appear as single large neoplasms with high malignant potential in patients without type A chronic atrophic gastritis, pernicious anaemia, or ZollingerEllison syndrome and have often metastasised at the time of diagnosis. ${ }^{3}$ 7-9 This type also include neuroendocrine carcinomas and mixed endocrine and exocrine tumours.

In the present study we investigated the correlation between type of gastric carcinoid and production of hormones, endocrine symptoms, the occurrence of metastases, and prognosis.

\section{Material and methods}

PATIENTS

Fifteen patients with histologically verified gastric carcinoids consecutively referred to our unit were included in the study. 
Table 1 Type 1 tumour characteristics in patients with and without pernicious anaemia

\begin{tabular}{|c|c|c|c|c|c|c|c|c|c|}
\hline Patient no & 1 & 2 & 3 & 4 & 5 & 6 & 7 & 8 & 9 \\
\hline Pernicious anaemia & No & Yes & Yes & No & Yes & Yes & $\mathrm{No}^{\star}$ & Yes & Yes \\
\hline Number of tumour(s) & Multiple & Multiple & Multiple & Solitary & Multiple & Multiple & Solitary & Multiple & Multiple \\
\hline Location of tumour(s) & Corpus & Fundus + corpus & Corpus & Fundus & Fundus + corpus & Fundus & Corpus & Corpus + bulbus & Corpus \\
\hline Depth of invasion & $\begin{array}{l}\text { Muscularis } \\
\text { mucosae }\end{array}$ & $\begin{array}{l}\text { Muscularis } \\
\text { mucosae }\end{array}$ & Submucosa & $\begin{array}{l}\text { Muscularis } \\
\text { mucosae }\end{array}$ & $?$ & $\begin{array}{l}\text { Lamina } \\
\text { propria }\end{array}$ & Submucosa & Submucosa & $\begin{array}{l}\text { Muscularis } \\
\text { mucosae }\end{array}$ \\
\hline Grimelius' silver stain & + & + & + & ND & + & + & + & + & + \\
\hline Chromogranin A stain & + & ND & + & + & ND & + & ND & + & ND \\
\hline Sevier-Munger stain & + & + & + & + & + & + & ND & - & ND \\
\hline
\end{tabular}

Patient $7^{\star}$ later developed pernicious anaemia. Patient 1 had multiple lymph node metastases and a liver metastasis at diagnosis.

+ , Positive; -, negative; ND, not done; ?, unclear.

Nine (six women and three men) had type 1 tumours according to the classification of Rindi et al. ${ }^{7}$ Median age at diagnosis was 52.2 (range 44.3-76.4) years. Table 1 summarises some characteristics of the tumours in the individual patients, including the presence or absence of pernicious anaemia. At the time of diagnosis, one patient had multiple lymph node metastases and a single metastasis in the liver, which was verified by needle biopsy. Median follow up was 97 (range 4-210) months.

One patient had type 2 gastric carcinoids. Her gastric tumour, which stained positively for chromogranin A antibodies, Grimelius' silver stain, calcitonin, pancreatic polypeptide, gastrin, and serotonin, was first observed at age 32. Liver metastases, verified at biopsy, were present at the initial diagnosis. She had recurrent gastric ulcers and was later found to have a prolactinoma and primary hyperparathyroidism, thus fulfilling the criteria for MEN 1. She was followed for 17 years from diagnosis of her gastric carcinoid.

Five patients (three men and two women) had type 3 gastric carcinoids according to the classification of Rindi et al..$^{7}$ Median age at diagnosis was 59.1 (range 56.1-70.7) years. All type 3 gastric carcinoids were chromogranin A positive and one was Sevier-Munger positive. One of the type 3 tumours was localised in the cardia, two in the corpus/fundus, one in the pyloric region and the last in the anastomosis after a Billroth II operation, carried out 32 years earlier because of a perforated duodenal ulcer. At diagnosis, all patients in this group had metastases to the lymph nodes and all but one had liver metastases; this last patient developed liver metastases within two years. Moreover, one patient had peritoneal metastases and in one patient bone metastases occurred two years after diagnosis. Median follow up among the type 3 patients was 7.4 (range 3-37) months.

\section{HORMONES}

After an overnight fast, blood samples were drawn for analysis of plasma chromogranin A, chromogranin $B$, serum gastrin, serum pancreatic polypeptide (PP), serum calcitonin, and serum human chorionic gonadotrophin subunits $\alpha$ and $\beta$ (hCG $\alpha$ and hCG $\beta$ ) as described previously. ${ }^{19-24}$ A 24 hour collection of urine was used for measurements of MeImAA excretion. Urinary 5-hydroxyindolacetic acid (5'HIAA) was usually collected for two consecutive 24 hour periods, and the mean value was calculated. Plasma tachykinins (neuropeptide $K$, substance $P$ ) and calcitonin gene related peptide were analysed in four patients in each group.

In one patient with a metastasising type 1 tumour, no hormone values were obtained before total gastrectomy, and in another type 1 patient a carcinoid polyp had been extirpated endoscopically before the hormone sampling. The patient with type 2 tumour had been subjected to antrectomy and vagotomy before the hormone analyses.

STATISTICS

Intergroup comparisons of hormones were carried out by the Mann-Whitney U test. Survivial analysis was made by Kaplan-Meier survival plots and Mantel-Cox log rank test. $\mathrm{p}<0.05$ was considered significant.

\section{Results}

HORMONES

Tables 2 and 3 present the results of the hormone analyses. Plasma chromogranin A and chromogranin $\mathrm{B}$ were increased in all patients, but both hormones were significantly higher in the patients with type 3 carcinoid than in those with type $1(\mathrm{p}<0.01$ and $\mathrm{p}=0.01$ respectively). Serum gastrin was slightly raised in one type 3 patient but moderately or greatly increased in all the type 1 patients $(\mathrm{p}<0.01)$. The type 2 patient had normal serum gastrin on admission but had been subjected to antrectomy several years previously. Urinary 5'HIAA was normal in all patients except for a moderate increase in one with the type 3 tumour. Urinary MeImAA was slightly or moderately increased in four of the five type 3 patients $(80 \%)$, in the type 2 patient, and in three of the nine $(33 \%)$ patients with type 1 carcinoids. The type 1 patient with moderately increased MeImAA had had a carcinoid polyp extirpated endoscopically two years previously, and, at the time of hormone analysis, no residual tumour could be detected, but atrophic gastritis, endocrine cell hyperplasia, and high serum gastrin were present. When controlled several years later, MeImAA was normal on two occasions without therapy, despite persisiting ECL cell hyperplasia and increased serum gastrin. Serum calcitonin was normal in all type 1 patients but greatly increased in the type 2 patient and slightly increased in two type 3 patients. A slight increase in serum PP was seen in four patients with type 1 tumour and one with type 3 ; in addition, one type 3 patient and the type 2 patient had greatly increased PP. In the last case, serum PP fell substantially after surgical reduction of the tumour burden. Serum hCG $\alpha$ 
Table 2 Hormone concentrations and endocrine symptoms in the patients with gastric carcinoids

\begin{tabular}{|c|c|c|c|c|c|c|c|c|c|c|c|c|c|c|c|c|}
\hline \multirow[b]{2}{*}{ Patient } & \multicolumn{9}{|l|}{ Type 1} & \multirow{2}{*}{$\begin{array}{l}\text { Type } 2 \\
10\end{array}$} & \multicolumn{5}{|c|}{ Type 3} & \multirow[t]{2}{*}{ Reference range } \\
\hline & 1 & 2 & 3 & 4 & 5 & 6 & 7 & 8 & 9 & & 11 & 12 & 13 & 14 & 15 & \\
\hline Chromogranin A (nmol/1) & 7.8 & 12 & 10.2 & 6 & 10.1 & 9.9 & 9.2 & 5.5 & 8.1 & 412 & $>512$ & 0146 & 16.4 & 53.1 & 92 & $<4$ \\
\hline Chromogranin B (nmol/l) & 3.3 & 2.9 & 2.4 & - & 2.4 & 2.3 & 2.5 & 2 & - & 3.4 & 13.8 & - & 3.1 & 6.1 & 5.7 & $<2$ \\
\hline Gastrin (pmol/l) & 6.1 & 344 & 392 & 600 & 462 & 630 & 1500 & 202 & 261 & 13.7 & - & 19.9 & 97 & 12 & 6.8 & $<55$ \\
\hline Calcitonin (ng/l) & 150 & $<3^{\star}$ & 160 & $<3^{\star}$ & $<3^{\star}$ & - & $<20 \dagger$ & 180 & - & 5200 & 180 & - & 180 & 490 & 670 & $<300$ \\
\hline $\mathrm{PP}(\mathrm{pmol} / \mathrm{l})$ & 138 & $<15$ & 18 & $<15$ & 17 & 120 & 69 & 17 & 89 & 2070 & 104 & 24 & 4875 & $<15$ & 46 & $<70$ \\
\hline $\mathrm{hCG} \alpha(\mathrm{mg} / \mathrm{l})$ & $0.63^{\star}$ & $3^{\star}$ & 2.1 & 0.6 & 2.2 & 1.08 & $5.8^{\star}$ & 1.9 & $2.3^{\star}$ & 0.82 & $99^{\star}$ & 7.1 & 0.22 & 1.66 & $0.82^{\star}$ & $<3$ \\
\hline Urinary 5'HIAA $(\mathrm{mmol} / 24 \mathrm{~h})$ & 13 & 20 & 36 & - & 45 & - & 23 & 35 & 18 & 48 & 22 & 130 & 24 & 47 & 18 & $10-80$ \\
\hline $\begin{array}{l}\text { Urinary MeImAA } \\
\text { (mmol/mol creatinine) }\end{array}$ & 3.4 & $1.1^{\star}$ & 1.1 & 0.9 & 4.6 & - & $16.4^{\star}$ & 1.8 & 1.1 & 17.9 & 7.8 & 1 & 10.5 & 2.8 & 3.9 & $0.4-2.4$ \\
\hline Endocrine symptoms & No & No & No & No & No & No & Flush & No & No & $\begin{array}{l}\text { Flush, } \\
\text { diarrhoea }\end{array}$ & No & No & No & No & No & \\
\hline
\end{tabular}

Patient 1 had undergone total gastrectomy at the time of the hormone analyses but had a radiologically visible liver metastasis, verified by needle biopsy. In patient 6 the carcinoid polyp had been extirpated endoscopically before the hormone measurement. Patient 10, having the MEN 1 syndrome, had undergone antrectomy before the hormone measurements.

* For patients 2, 4 and 5, indicated with an asterisk, the calcitonin reference range was $<10 \mathrm{ng} / \mathrm{l}$ and for tpatient 7 it was $<20 \mathrm{ng} / \mathrm{l}$ because of the different methods of analysis; ${ }^{\star}$ for the postmenopausal women the $\mathrm{hCG} \alpha$ reference range was $<8.5 \mathrm{mg} / 1$ and ${ }^{\star}$ for patients 2 and 7 the urinary MeImAA reference range was $2-4 \mathrm{mg} / 24 \mathrm{~h}$. PP, pancreatic peptide; 5'HIAA, 5'-hydroxyindolacetic acid; MeImAA, tele-methylimidazoleacetic acid; hCG $\alpha, \alpha$ subunit of human chorionic gonadotrophin; -, not analysed.

and hCG $\beta$ were normal in all patients except for two with type 3 carcinoids; one had greatly and the other slightly increased hCG $\alpha$. Moreover, during the disease course, hCG $\beta$ increased to moderately high levels in the patient with MEN 1. Tachykinins were normal in all patients tested except for one type 3 patient without the carcinoid syndrome.

SYMPTOMS (TABLES 2 AND 3)

Four of the type 3 carcinoids were detected at gastroscopy carried out because of abdominal pain, and in the fifth patient the tumour was seen en passant at laparotomy carried out to remove a benign renal tumour. In the type 2 patient the gastric carcinoid was diagnosed at microscopic examination after Billroth I resection of the stomach because of a bleeding ulcer on the minor curvature. In four patients being investigated for anaemia, type 1 tumours were detected by gastroscopy. All but two of the patients with type 1 carcinoids had gastrointestinal symptoms such as nausea, vomiting, and abdominal pain.

The combination of flush and diarrhoea was only seen in the MEN 1 patient. She had moderately increased MeImAA and greatly increased calcitonin but normal 5'HIAA and tachykinins. The type 3 patient with high 5'HIAA had normal MeImAA and no endocrine symptoms. The type 1 patient with initially moderately high MeImAA but normal

Table 3 Summary of the main differences between type 1 and type 3 carcinoid tumours

\begin{tabular}{|c|c|c|c|}
\hline & Type 1 & Type 3 & $p$ Value \\
\hline Major symptoms & $\begin{array}{l}\text { Pernicious anaemia, epigastric pain, nausea, } \\
\text { vomiting }\end{array}$ & $\begin{array}{l}\text { Abdominal } \\
\text { pain }\end{array}$ & \\
\hline $\begin{array}{l}\text { Plasma } \\
\text { chromogranin } \\
\text { A (nmol/l) }\end{array}$ & 9.7 & 92 & $<0.01$ \\
\hline $\begin{array}{l}\text { Plasma } \\
\text { chromogranin } \\
\text { B }(\mathrm{nmol} / \mathrm{l})\end{array}$ & 2.4 & 5.9 & 0.01 \\
\hline $\begin{array}{l}\text { Serum gastrin } \\
(\mathrm{pmol} / \mathrm{l})\end{array}$ & 427 & 16 & $<0.01$ \\
\hline $\begin{array}{l}\text { Urinary } \\
\text { MeImAA } \\
\text { (mmol/mol } \\
\text { creatinine) }\end{array}$ & 1.1 & 3.9 & 0.2 \\
\hline $\begin{array}{l}\text { Survival } \\
\text { (months) }\end{array}$ & 97 & 7.4 & 0.0001 \\
\hline
\end{tabular}

Hormone and survival values are medians. One patient (no 1 in table 2) was excluded from the hormone calculations as no values were obtained before surgery.

MeImAA, tele-methylimidazoleacetic acid.
5'HIAA had flushing, which persisted despite normalisation of the MeImAA level.

\section{TREATMENT AND PROGNOSIS}

Type 1

In a 74 year old woman (patient no 1 in tables 1 and 2) with anorexia, nausea, and vomiting, endoscopy showed a gastric tumour which was classified as small cell adenocarcinoma. At laparotomy, lymph node metastases and a single metastasis in the liver were found. Total gastrectomy was performed, the lymph node metastases were removed, and a needle biopsy sample was taken from the liver metastasis showing carcinoid tumour. Microscopic examination of the stomach disclosed chronic atrophic gastritis with intestinal metaplasia, endocrine cell hyperplasia, and multiple mucosal carcinoid tumours. On admission, she had slightly increased chromogranin A (7.8 $\mathrm{nmol} / \mathrm{l})$, chromogranin $\mathrm{B}(3.3 \mathrm{nmol} / \mathrm{l})$, and PP (138 pmol/1). The liver metastasis was visible on ultrasonography (fig 1A). Treatment was started with interferon $\alpha$ at a dose of $3 \times 3$ $\mathrm{MU} /$ week subcutaneously, and three months later octreotide $2 \times 100 \mu \mathrm{g} /$ day subcutaneously was added. Nine months after interferon and six months after octreotide therapy was started, the results of ultrasonography of the liver were normal (fig 1B), and after another three months, chromogranin A was normalised. Interferon was administered for a total of one and a half years and was then withdrawn, but octreotide was continued. PP normalised two and a half years after the start of treatment. The patient is still alive eight years after diagnosis, continuing with octreotide treatment, without either biochemical or radiological signs of tumour recurrence. Figure 2 shows the course of treatment and disease.

Total gastrectomy was performed in another patient (no 2 in tables 1 and 2) who had multiple locally invasive carcinoids. She is free of recurrence without additional treatment. In patient no 7, a carcinoid polyp was extirpated endoscopically; at an extended surgical resection no residual tumour was found. She has received hydrochloric acid in an effort to suppress serum gastrin. Despite unaltered high serum gastrin and persisting endocrine cell hyperplasia, she has no residual carcinoid 

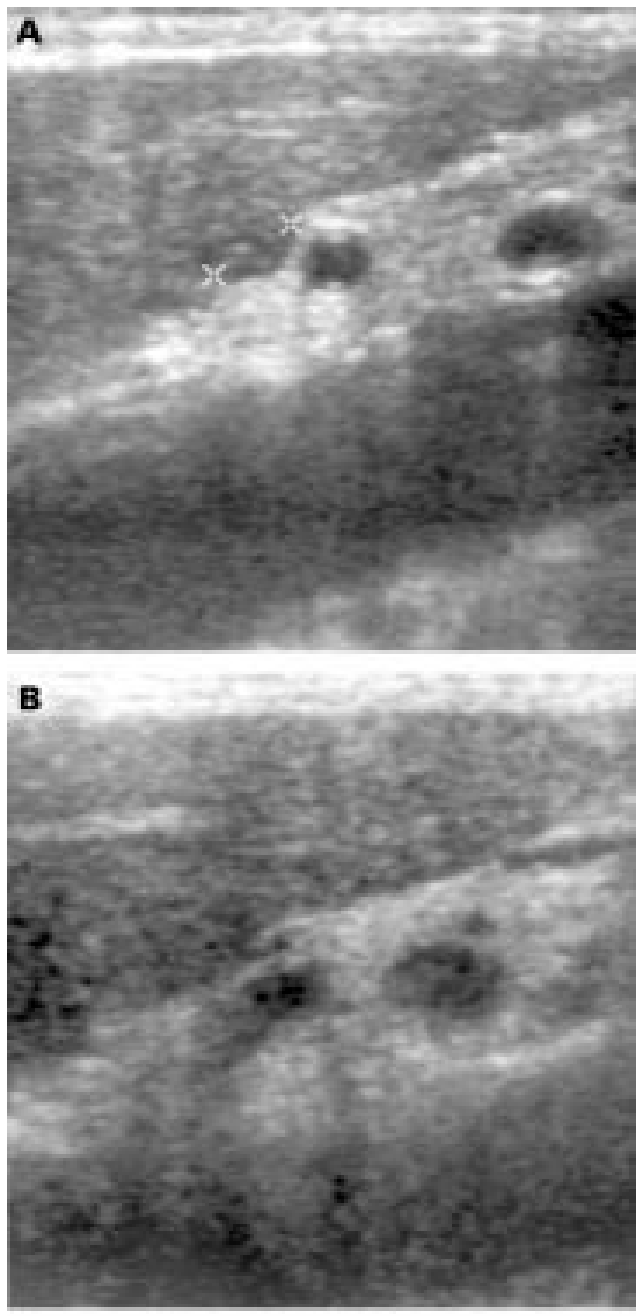

Figure 1 Ultrasonograph of the liver of a patient with type 1 carcinoids $(A)$ before treatment started showing a metastasis of about $1 \mathrm{~cm}$ (between the crosses) and (B) after nine months of interferon a therapy, when the metastasis is no longer visible.

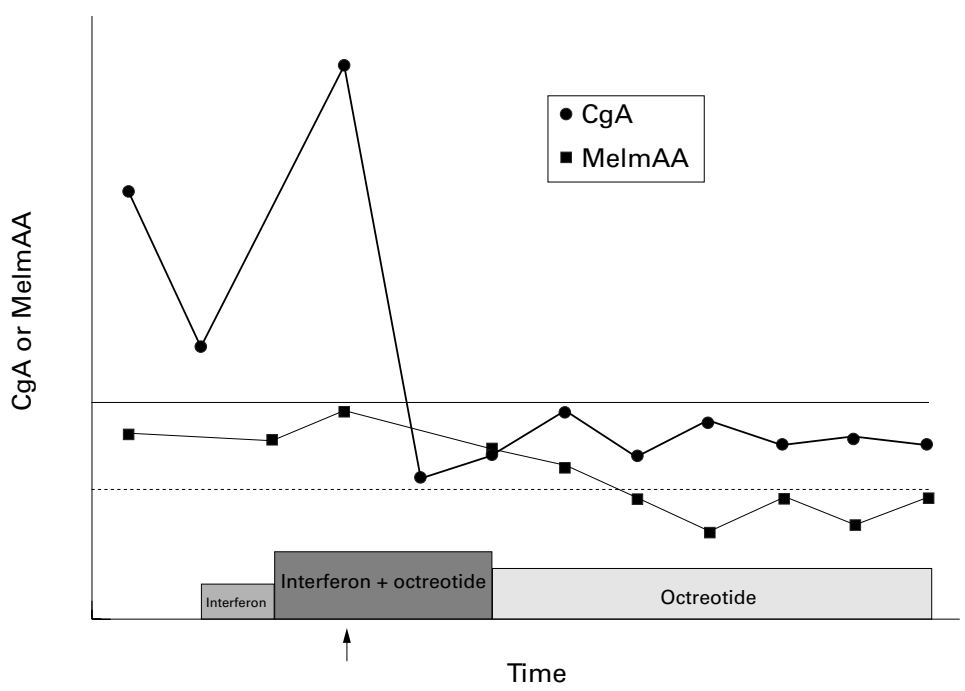

Figure 2 Chromogranin $A(C g A)$ and MeImAA in the patient with type 1 tumour with a liver metastasis that disappeared during medical treatment. The solid line shows the upper normal range for chromogranin $A$ and the dotted line the upper normal range for MeImAA. The arrow indicates the time at which the liver metastasis was no longer visible on ultrasound examination of the liver. disease. Patient no 3 had a gastric carcinoid removed at laparotomy. After the operation she received hydrochloric acid without effect on the serum gastrin levels. Since ECLomas recurred, she underwent antrectomy and is free of disease two and a half years later. Another patient (no 6) who is treated with hydrochloric acid without suppressive effect on the serum gastrin levels also has recurrent ECLomas; this patient has not received surgery but is closely monitored with regular hormone analyses and endoscopic examinations. Patient no 8 , also receiving hydrochloric acid with no effect on serum gastrin level, has developed a carcinoid with positive staining for gastrin in the duodenum, and therefore has two endocrine tumour diseases. Patient no 4 is the only one in which treatment with hydrochloric acid has caused reduction in serum gastrin (from 600 to 281 $\mathrm{pmol} / \mathrm{l}$ ); the disease has not yet been controlled with gastroscopy. Plasma chromogranin A levels were unaltered in all the patients during hydrochloric acid therapy, but decreased after antrectomy $(\mathrm{p}<0.05)$. Finally, one patient (no 5) was treated with octreotide $2 \times 100 \mu \mathrm{g} /$ day subcutaneously for nearly a year, resulting in a reduction in chromogranin A from 10.1 to 2.6 $\mathrm{nmol} / \mathrm{l}$; the treatment was stopped because of diarrhoea. The last patient with ECLoma (no 9) has received no treatment as yet.

\section{Type 2}

The single patient with this type of tumour was subjected to antrectomy and truncal vagotomy because of recurrent gastric ulcers. A gastric carcinoid with liver metastases was found. She later presented with multiple metastatic gastric tumours. To reduce the tumour burden, the gastric tumours and some of the metastases were removed. The postoperative period was complicated and she died nearly eight months later.

\section{Type 3}

One patient with unresectable tumour was treated with interferon $\alpha$ for one year as a single drug and then in combination with different chemotherapy regimens (5-fluorouracil, streptozotocin + 5-fluorouracil, and finally fotemustine). An arterial embolisation of the liver was also performed with gel foam. Stable disease was noted during short periods. This patient survived for three years after diagnosis. Medical treatment (interferon $\alpha$, interferon $\gamma$, or octreotide) was tried in the others without success. One patient whose gastric tumour was discovered accidentally at surgery for a benign renal tumour was also subjected to a Billroth I resection of the stomach. Microscopic examination showed lymph node metastases, and, two years later, liver metastases developed.

\section{SURVIVAL}

Figure 3 gives survival data. One patient with type 1 carcinoid and severe scleroderma died from myocardial infarction 3.8 years after the carcinoid diagnosis; all the other type 1 patients are alive after a median observation time of 105 (range 4-210) months. The type 2 patient died 17 years after diagnosis. All the type 3 patients 


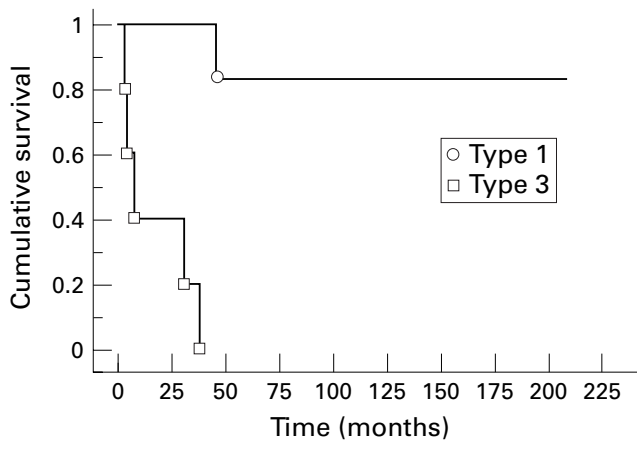

Figure 3 Cumulative survival (Kaplan-Meier plot) in patients with type 1 and type 3 gastric carcinoids.

died as the result of metastastic disease; median survival time was 7.4 (range 3-37) months, which was significantly shorter $(p=0.0001)$ than in type 1 .

\section{Discussion}

With the exception of slightly increased MeImAA or PP, hormone overproduction was rare among the type 1 patients. In contrast, type 3 tumours commonly produced various hormones. MeImAA was increased in four of the five patients with these tumours, and increased PP, calcitonin, and hCG $\alpha$ was also frequent. Although expression of $\mathrm{hCG} \alpha$ has been claimed to occur almost exclusively in fundic endocrine cells exposed to hypergastinaemia, ${ }^{25-27}$ none of our type 1 patients had increased serum hCG $\alpha$ levels, which was found only in metastatic type 3 gastric carcinoid patients with short survival (seven and four months from diagnosis respectively). Whether hCG $\alpha$ has a pathogenetic role in the proliferation of gastric endocrine cells is still unclear, but elevated serum hCG $\alpha$ levels may be an indication of a more aggressive tumour type. This has been reported previously for malignant islet cell tumours. ${ }^{28}$ Urinary 5'HIAA was increased only in one type 3 patient and seems not to be useful as a tumour marker for gastric carcinoids.

Both chromogranin A and chromogranin B were increased in all patients, but were considerably higher in the patients with type 3 tumours than in those with type 1 . This probably reflects the larger tumour burden in the former group. In midgut carcinoids, plasma chromogranin A concentration correlates with tumour size but is also an independent predictor of survival. ${ }^{29}$ If chromogranin A does have a pathogenetic impact on survival in gastric carcinoids, it is not possible to confirm this because of the scant patient material in the present study.

The most effective treatment of type 1 gastric carcinoids is under discussion. Spontaneous resolution has been described. ${ }^{30}$ Limited surgery with endoscopic polypectomy and/or antrectomy aimed at reducing the high serum gastrin levels have been proposed by several authors, ${ }^{361231-33}$ and in one study antrectomy led to rapid regression of ECL cell carcinoids in three of three patients. ${ }^{31}$ Two of our patients were subjected to total gastrectomy, one (who was found to have metastases at operation) because the initial diagnosis was adenocarcinoma and the other (12 years ago) because of infiltrative carcinoids penetrating the muscularis mucosae. According to later experience, antrectomy may have been as effective in the latter patient. An attempt was made in five patients to suppress gastrin production by substituting hydrochloric acid, but gastrin levels were only successfully decreased in one of them. Endocrine cell hyperplasia persisted in three patients, and two of them developed new ECL cell tumours. Although hydrochloric acid substitution did not prevent the occurrence of new carcinoids, it may be considered for patients who are not suitable for surgery. This view is supported by the low metastatic potential of ECL cell derived gastric carcinoids. Furthermore, clinical well being is often improved by acid substitution.

Treatment with interferon $\alpha$ or octreotide or both is well documented for malignant midgut carcinoids and endocrine pancreatic tumours and can sometimes decrease the size of metastases. ${ }^{34-36}$ Octreotide has also been shown to decrease ECL cell content and plasma gastrin levels in patients with chronic atrophic type A gastritis. ${ }^{27}$ Total regression of liver metastases in a patient with foregut carcinoids during medical treatment has, however, not previously been described. Our patient with metastasising type 1 gastric carcinoid has normal hormone levels 5.8 years after withdrawal of interferon, and no metastases are visible on ultrasound examination of the abdomen nor at pulmonary $x$ ray or bone scintigraphy. Although the disappearance of the liver metastasis may also be a consequence of the normalised serum gastrin levels after gastrectomy, a combination of interferon $\alpha$ and octreotide should be considered in patients with malignant type 1 tumours.

Type 3 gastric carcinoids are known to be malignant tumours. ${ }^{3-9}$ All of our patients with this type of tumour had metastases at the time of diagnosis and died of widespread disease. In contrast, only one of the patients with type 1 carcinoids has developed metastases, and none in this group has died as a result of their carcinoids. Despite liver metastases at the initial diagnosis, the patient with MEN 1 survived far longer than the type 3 patients. Since no pancreatic tumour could be found at laparotomy despite the use of intraoperative ultrasound examination and the liver metastases showing similar immunoreactivity on histological examination to the gastric carcinoid, this tumour is believed to be the origin of the liver metastases. Previous reports showed a better prognosis for MEN 1 derived endocrine pancreatic tumours than for sporadic cases, indicating different tumour biology, earlier diagnosis, or greater sensitivity to therapy including interferon. ${ }^{37}$

Patients with type 3 gastric carcinoids have significantly shorter survival $(p<0.001)$ than type 1 patients, indicating a different tumour biology. These patients should be carefully monitored for development of recurrent disease after primary resection. Both plasma chromogranin A and chromogranin B appear 
to be "candidate" markers to follow later on. If either of these are increased, the biochemical screening should then also include serum calcitonin, PP, hCG $\alpha$, and urinary MeImAA. In future, careful analysis of the expression of growth factors/receptors, adhesion molecules, and angiogenic factors may give a stronger base for clinical intervention.

1 Williams ED, Sandler M. The classification of carcinoid tumors. Lancet 1963;1:238-9.

2 Granerus G, Lindell SE, Waldenström J, et al. Histamine metabolism in carcinoidosis. Lancet 1966:1267-8.

3 Bordi C, Baggi MT, Davoli C, et al. Gastric carcinoids and their precursor lesions. A histologic and immunohistochemical study of 23 cases. Cancer 1991;67:663-72.

4 Grigioni WF, Caletti GC, Gabrielli M, et al. Gastric carcinoids of ECL cells. Pathological and clinical analysis of eight cases. Acta Pathologica faponica 1985;35:361-75.

5 Lehy T, Cadiot G, Mignon M, et al. Influence of multiple eny T, Cadiot G, Mignon M, et al. Influence of multiple
endocrine neoplasia type 1 on gastric endocrine cells in endocrine neoplasia type 1 on gastric endocrine cells in
patients with the Zollinger-Ellison syndrome. Gut 1992; patients with

6 Müller J, Kirchner T, Müller-Hermelink HK. Gastric endocrine cell hyperplasia and carcinoid tumors in atrophic gastritis type A. Am f Surg Pathol 1987;11:909-17.

7 Rindi G, Luinetti O, Cornaggia M, et al. Three subtypes of gastric argyrophil carcinoid and the gastric neuroendocrine carcinoma: a clinicopathologic study. Gastroenterology 1993;104:994-1006.

8 Solcia E, Capella C, Sessa F, et al. Gastric carcinoids and related endocrine growths. Digestion 1986;35(suppl 1):322.

9 Solcia E, Capella C, Fiocca R, et al. The gastroenteropancreatic endocrine system and related tumors. Gastroenterol Clin North Am 1989;18:671-93.

10 Solcia E, Capella C, Buffa R, et al. Endocrine cells of the gastrointestinal tract and related tumors. Pathobiology Annual 1979;9:163-204

11 Wilander E, El-Salhy M, Pitkänen P. Histopathology of gastric carcinoids: a survey of 42 cases. Histopathology 1984;8. tric carcin.

12 Borch K, Renvall H, Liedberg G. Gastric endocrine cell hyperplasia and carcinoid tumors in pernicious anemia Gastroenterology 1985;88:638-48.

13 Thomas RM, Baybick JH, Elsayed AM, et al. Gastric carcinoids. An immunohistochemical and clinicopathologic study of 104 patients. Cancer 1994;73:2053-8.

14 Creutzfeldt W. The achlorhydria-carcinoid sequence: role of gastrin. Digestion 1988;39:61-79.

15 Wilander E, Nordgren H, Öberg K. Nonantral gastric carcinoid tumors associated with hypergastrinemia. Acta Med Scand 1986;219:393-7.

16 Solcia E, Bordi C, Creutzfeldt W, et al. Histopathological classification of nonantral gastric endocrine growths in man. Digestion 1988;41:185-200.

17 Carney JA, Go VLW, Fairbanks VF, et al. The syndrome of gastric argyrophil carcinoid tumors and nonantral gastric gastric argyrophil carcinoid tumors and
atrophy. Ann Intern Med 1983;99:761-6.

18 Solcia E, Capella C, Fiocca R, et al. Gastric argyrophil carcinoidosis in patients with Zollinger-Ellison syndrome due to type 1 multiple endocrine neoplasia. Am $\mathcal{F}$ Surg Patho 1990;14:503-13.

19 Stridsberg M, Hellman U, Wilander E, et al. Fragments of chromogranin A are present in the urine of patients with carcinoid tumors: development of a specific radioimmunoassay for chromogranin A and its fragments. $\mathcal{F}$ Endocrinol 1993;139:329-37.

20 Stridsberg M, Öberg K, Li Q, et al. Measurement of chromogranin A, chromogranin B (secretogranin I), chromogranin C (secretogranin II) and pancreastatin in plasma and urine from patients with carcinoid tumours and endocrine pancreatic tumours. F Endocrinol 1995;144:49-59.

21 Lundqvist G, Wide L. Serum gastrin determination with a radioimmunosorbent technique. Clin Chim Acta 1977;79: 357-62.

22 Hällgren R, Lundqvist G, Chance RE. Serum levels of human pancreatic polypeptide in renal disease. Scand $\mathcal{F}$ Gastroenterol 1977;12:923-7.

23 Almqvist S, Telenius-Berg M, Wästhed B. Serum calcitonin in medullary thyroid carcinoma. Acta Medica Scandinavica 1974;196:177-80.

24 Öberg K, Wide L. HCG and HCG-subunits as tumour markers in patients with endocrine pancreatic tumours and carcinoids. Acta Endocrinologica (Copenhagen) 1981;98: 256-60.

25 Bordi C, Paolo Pilato F, Bertelé A, et al. Expression of glycoprotein hormone alpha-subunit by endocrine cells of the oxyntic mucosa is associated with hypergastrinemia. Hum Pathol 1988;19:580-5.

26 Solcia E, Fiocca R, Villani L, et al. Morphology and pathogenesis of endocrine hyperplasias, precarcinoid lesions, and carcinoids arising in chronic atrophic gastritis. Scand $\mathcal{f}$ Gastroenterol 1991;26(suppl 180):146-59.

27 Ferraro G, Annibale B, Marignani M, et al. Effectiveness of octreotide in controlling fasting hypergastrinemia and related enterochromaffin-like cell growth. $\mathcal{F}$ Clin Endocrinol Metab 1996;81:677-83.

28 Kahn CR, Rosen SW, Weintraub BD, et al. Ectopic production of chorionic gonadotropin and its subunits by islet-cell tumors. A specific marker for malignancy. $N$ Engl $\mathcal{F} \mathrm{Med}$ 1977;297:565-9.

29 Tiensuu Janson E, Holmberg L, Stridsberg M, et al. Carcinoid tumors: analysis of prognostic factors and survival in 301 patients from a referral center. Ann Oncol 1997;8:68590 .

30 Harvey RF. Spontaneous resolution of multifocal gastric enterochromaffin-like cell carcinoid tumours. Lancet 1988; i: 821 .

31 Hirschowitz BI, Griffith J, Pellegrin D, et al. Rapid regression of enterochromaffinlike cell gastric carcinoids in pernicious anemia after antrectomy. Gastroenterology 1992; 102:1409-18.

32 McAleese P, Moorehead J. Multiple gastric carcinoid tumours in a patient with pernicious anemia: endoscopic removal or gastric resection? Eur f Surg 1994;160:243-6.

33 Thirlby RC. Management of patients with gastric carcinoid tumors. Gastroenterology 1995;108:296-7.

34 Eriksson B, Skogseid B, Lundqvist G, et al. Medical treatment and long-term survival in a prospective study of 84 patients with endocrine pancreatic tumors. Cancer 1990;65:1883-90.

35 Öberg K, Eriksson B. Medical treatment of neuroendocrine gut and pancreatic tumors. Acta Oncol 1989;28:425-31.

36 Tiensuu Janson EM, Ahlström H, Andersson T, et al. Octreotide and interferon-alpha: a new combination for the treatment of malignant carcinoid tumors. Eur $\mathcal{f}$ Cancer 1992;28A: $1647-50$.

37 Eriksson B, Öberg K, Skogseid B. Neuroendocrine pancreatic tumors: clinical findings in a prospective study of 84 patients. Acta Oncol 1989;28:373-7. 